\title{
Relationship between Nutritional Support and Tuberculosis Treatment Outcomes in West Bengal, India
}

\author{
Blesson Samuel ${ }^{*}$, Tyson Volkmann², Sushma Cornelius ${ }^{1}$, Sugata Mukhopadhay1, MejoJose ${ }^{1}$, \\ Kaushik Mitra ${ }^{3}$, Ajay M. V. Kumar', John E. Oeltmann², Sidhajyoti Parija5, \\ Aslesh Ottapura Prabhakaran', Patrick K. Moonan' ${ }^{2}$, Vineet K. Chadha7
}

\author{
${ }^{1}$ World Vision India, New Delhi, India \\ ${ }^{2}$ Centers for Disease Control and Prevention, Atlanta, USA \\ ${ }^{3}$ Burdwan Medical College, West Bengal, India \\ ${ }^{4}$ International Union against Tuberculosis and Lung Disease, South-East Asia Regional Office, New Delhi, India \\ ${ }^{5}$ Southern Health Improvement Samity, West Bengal, India \\ ${ }^{6}$ Department of Community Medicine, Academy of Medical Sciences, Pariyaram, India \\ ${ }^{7}$ Epidemiology and Research Division, National Tuberculosis Institute, Bangalore, India \\ Email: ^blessonsamuel81@gmail.com
}

How to cite this paper: Samuel, B., Volkmann, T., Cornelius, S., Mukhopadhay, S., MejoJose, Mitra, K., Kumar, A.M.V., Oeltmann, J.E., Parija, S., Prabhakaran, A.O., Moonan, P.K. and Chadha, V.K. (2016) Relationship between Nutritional Support and Tuberculosis Treatment Outcomes in West Bengal, India. Journal of Tuberculosis Research, 4, 213-219.

http://dx.doi.org/10.4236/jtr.2016.44023

Received: November 23, 2016 Accepted: December 18, 2016

Published: December 21, 2016

Copyright $\odot 2016$ by authors and Scientific Research Publishing Inc. This work is licensed under the Creative Commons Attribution International License (CC BY 4.0).

http://creativecommons.org/licenses/by/4.0/ (c) (i) Open Access

\begin{abstract}
Introduction: Poverty and poor nutrition are associated with the risk of developing tuberculosis (TB). Socioeconomic factors may interfere with anti-tuberculosis treatment compliance and its outcome. We examined whether providing nutritional support (monthly supply of rice and lentil beans) to TB patients who live below the poverty line was associated with TB treatment outcome. Methods: This was a retrospective cohort study of sputum smear-positive pulmonary TB patients living below the poverty line (income of $<\$ 1.25$ per day) registered for anti-tuberculosis treatment in two rural districts of West Bengal, India during 2012 to 2013. We compared treatment outcomes among patients who received nutritional support with those who did not. A log-binomial regression model was used to assess the relation between nutritional support and unsuccessful treatment outcome (loss-to-follow-up, treatment failure and death). Results: Of $173 \mathrm{~TB}$ patients provided nutritional support, 15 (9\%) had unsuccessful treatment outcomes, while $84(21 \%)$ of the 400 not provided nutrition support had unsuccessful treatment outcomes $(\mathrm{p}<0.001)$. After adjusting for age, sex and previous treatment, those who received nutritional support had a $50 \%$ reduced risk of unsuccessful treatment outcome than those who did not receive nutritional support (Relative Risk: 0.51; 95\% Confidence Intervals: 0.30 0.86). Conclusion: Under programmatic conditions, monthly rations of rice and lentils were associated with lower risk of unsuccessful treatment outcome among
\end{abstract}


impoverished TB patients. Given the relatively small financial commitment needed per patient ( $\$ 10$ per patient per month), the national TB programme should consider scaling up nutritional support among TB patients living below the poverty line.

\section{Keywords}

Nutritional Support, Poverty, Pulmonary Tuberculosis, India

\section{Introduction}

India has the highest tuberculosis (TB) incidence in the world in terms of absolute numbers. In 2014, about 2 million people in India are estimated to have developed TB disease $-22 \%$ of the 9 million TB cases worldwide [1]. Poverty has been long associated both with under-nutrition and TB [2] [3] [4]. Lack of access to basic health services, food insecurity and inadequate living conditions fuels TB transmission. A vicious relationship exists between poverty and TB; the impoverished are at greater risk of TB, and those with TB are at greater risk of becoming impoverished [2] [4]. Studies suggest that the average TB patient loses three to four months of individual and household income due to incapacitation and while seeking diagnosis and treatment [5] [6]. For people living below poverty line (BPL) ( $<$ US $\$ 1.25$ per day), this could mean the difference between feeding themselves and their families or complying with anti-tuberculosis treatment-a minimum course of at least 6 months. Nutrition plays an important role in general well-being but also healing from infections like M. tuberculosis [7] [8]. Unfortunately, the impoverished suffer from high rates of under-nutrition, which besides being risk factor for development of TB disease, can also adversely affect outcomes of TB treatment [9] [10] [11].

In studies from India, the impoverished were twice as likely to have $\mathrm{TB}$, three times less likely to access TB care, four times less likely to complete anti-tuberculosis treatment, and more likely to incur impoverishing payments for TB care than the non-im-

poverished [12] [13]. The risk of mortality during anti-tuberculosis treatment among severely undernourished patients was double that of non-undernourished patients in rural and central India [14].

While provision of free food has been shown to increase weight during treatment and improve quality of life, there is conflicting evidence if it improves TB treatment outcomes, with some trials showing benefit and others not [14] [15] [16] [17]. Hence, we aimed to determine if, among the poor, nutritional support was associated with treatment outcome among pulmonary TB patients, in select TB units in West Bengal, India.

\section{Methods}

\subsection{Setting}

The study was conducted in two districts in West Bengal, India-South 24 Parganas 
and North 24 Parganas having populations of 8.2 million and 10.1 million respectively, as per the District census in 2011 [18]. About 82\% of the households in rural North 24 Parganas suffered from food insecurity and $32 \%$ of the population lived below the poverty line [19]. In South 24 Parganas, 35\% of the population lived below the poverty line. [20].

In two tuberculosis units (TUs), one in each district, a non-profit organization called Southern Health Improvement Samitee (SHIS) provided monthly allotments of rice (13 kilograms) and lentil beans (3 kilograms) at no cost to TB patients for a period ranging from 60 to 90 days. A line-list of patient names from SHIS was used to determine who received nutritional support and who did not. No other organization provided any nutritional support to the selected TB patients during the study period, nor was any free nutrition provided to any TB patients during treatment by the government.

\subsection{Study Design, Study Population and Study Period}

This was a retrospective cohort study of newly diagnosed and previously treated sputum smear-positive, pulmonary TB patients living below the poverty line registered for anti-tuberculosis treatment in four tuberculosis units during 2012-2013. Patients with monthly income below 3000 INR $(<$ US $\$ 46)$ were considered living below the poverty line, or impoverished. Patients with extra-pulmonary disease, multidrug-resistant tuberculosis, or with monthly incomes above 3000 INR were excluded from analysis.

Given Nutrition support group: In the two TUs where nutritional support was being implemented, a line list of patients who actually received the support was obtained from SHIS.

Not given Nutrition support group: A sample of TB patients (i.e., every second patient) that lived below the poverty line from two TUs of the districts who did not receive free food support was considered the non-intervention group. Non-intervention TUs were selected due to their location near to the intervention TUs. In total there are 17 TUs in South 24 Praganas and 21 TUs in the District North 24 Praganas. To increase the power of the study, twice as many patients in the non-intervention group as compared to intervention group were selected for enrolment. A line listing of $400 \mathrm{BPL}$ TB patients with an income of below INR 3000 per month and who had not received nutrition was validated through senior treatment supervisors (STS). The estimated sample size was attained by including all patients registered under RNTCP at these facilities during 2012-2013.

Outcome: Treatment outcomes were recorded for all patients from the national TB programme registers. Completing six months of anti-tuberculosis treatment with or without having at least two sputum smear-negative test results by month six or eight of treatment were considered successful outcomes. Loss-to-follow-up (i.e., missing two months or more of anti-tuberculosis treatment consecutively), treatment failure (i.e., sputum smear-positive test results at month 5 or more after starting anti-tuberculosis treatment), or death during anti-tuberculosis treatment was considered unsuccessful outcomes. 
Study variables and sources of data: The following patient characteristics were extracted from the national TB programme registers to be used in this analysis: sex, age, year registered, treatment outcome, type of patient and treatment outcome.

\subsection{Statistical Methods}

We compared differences in the proportion of patient with unsuccessful treatment outcome by nutritional support, sex, age group, Type of TB patient (newly diagnosed, previously treated), year registered, using chi-square test. A $p$ value of $<0.05$ was considered statistically significant. A log-binomial regression model was used to calculate adjusted relative risk (RR) and 95\% confidence intervals (CI) to find out the association between nutritional support and unsuccessful treatment outcome if any.

\section{Results}

In the two TUs where nutrition support was provided, a total of $737 \mathrm{~TB}$ patients living below the poverty line were registered for anti-tuberculosis treatment during 20122013. Among the 315 BPL patients who received nutritional support, 142 (45\%) had extra-pulmonary disease or MDR-TB and were excluded. Thus, a total of 173 pulmonary $\mathrm{TB}$ patients who received nutritional support and anti-TB treatment under RNTCP with first line drugs were included in analysis. In the TUs not implementing nutritional support, $1062 \mathrm{~TB}$ patients living below the poverty line were registered for anti-tuberculosis treatment during 2012-2013. A total of 400 pulmonary, non-MDR TB patients were selected.

Of the 573 patients included in the analysis, 159 (28\%) were female and 417 (72\%) were male (Table 1) and 347 (61\%) were less than 45 years old. There were 479 (84\%) new cases and $94(16 \%)$ retreatment cases. The baseline characteristics of intervention and non-intervention group were similar by age, sex, history of treatment (Table $1)$.

Of the 173 TB patients who were supported by nutrition, 15 (9\%) had unsuccessful treatment outcomes, and $84(21 \%)$ of those who were not provided nutrition support had unsuccessful treatment outcomes ( $\mathrm{p}<0.001$ ) (RR: 0.41; 95\% CI: 0.21 - 0.60).

After adjusting for age, sex, and previous treatment, those receiving nutritional support had nearly a $50 \%$ lesser risk of unsuccessful treatment outcome than those who did not receive nutritional support (RR: $0.51 ; 95 \%$ CI: 0.30 - 0.86).

\section{Discussion}

This study found that food support for patients living below the poverty line was associated with lower risk of unsuccessful TB treatment outcomes. While some studies have asserted that food support interventions might have the potential to improve adherence to TB treatment, evidence concerning the effect of nutritional support on TB outcomes is sparse. In our study, the simple provision of US $\$ 10$ of rice and lentil beans provided once a month was associated with a significantly lower risk of unsuccessful treatment outcomes, even after adjusting for known co-factors. 
Table 1. Baseline characteristics of BPL TB patients (stratified by nutritional support) registered in West Bengal, India, $2012-2013$.

\begin{tabular}{|c|c|c|c|c|}
\hline Characteristic & Nutritional support (\%) & No nutritional support (\%) & Total (\%) & P-value \\
\hline Total & $173(30)$ & $400(70)$ & $573(100)$ & -- \\
\hline \multicolumn{5}{|l|}{ Sex } \\
\hline Female & $50(29)$ & $106(27)$ & $159(27)$ & 0.55 \\
\hline Male & $123(71)$ & $294(74)$ & $417(73)$ & \\
\hline \multicolumn{5}{|l|}{ Age (in years) } \\
\hline$<15$ & $2(1)$ & $4(1)$ & $6(1)$ & 0.99 \\
\hline $15-44$ & $102(59)$ & $239(60)$ & $341(60)$ & \\
\hline $45-64$ & $51(30)$ & $117(29)$ & $168(29)$ & \\
\hline $65+$ & $18(10)$ & $40(10)$ & $58(10)$ & \\
\hline \multicolumn{5}{|l|}{ TB classification } \\
\hline New & $141(82)$ & $338(85)$ & $479(84)$ & 0.37 \\
\hline Previously treated & $32(19)$ & $62(16)$ & $94(16)$ & \\
\hline \multicolumn{5}{|c|}{ Treatment outcome (combined) } \\
\hline Successful & $158(91)$ & $316(79)$ & $99(17)$ & $<0.001$ \\
\hline Unsuccessful & $15(9)$ & $84(21)$ & $474(83)$ & \\
\hline \multicolumn{5}{|c|}{ Treatment Outcome (disaggregated) } \\
\hline Cure & $130(75)$ & $220(55)$ & $350(61)$ & $<0.001$ \\
\hline Treatment completed & $28(16)$ & $96(24)$ & $124(22)$ & \\
\hline Lost to follow up & $1(1)$ & $41(10)$ & $42(7)$ & \\
\hline Failure & $6(4)$ & $10(3)$ & $16(3)$ & \\
\hline Death & $8(5)$ & $33(8)$ & $41(7)$ & \\
\hline
\end{tabular}

The results should be interpreted with caution given the inherent limitations of an observational study. While the intervention and non-intervention groups were similar with respect to age, sex and previous history of treatment, we do not have information about other possible co-factors (HIV status, diabetes mellitus, tobacco smoking, alcohol intake, baseline nutritional status, and disease severity). The classification of living below the poverty line was based on self-reported income data. We were unable to conduct multivariate analysis on the disaggregated treatment outcomes because small numbers of patients receiving nutrition died, were lost to follow up, or failed to treat. Another limitation relates to lack of information on long-term treatment outcomes like relapse given the reliance of the study on routinely collected data. We plan to follow these cohorts to see if improved treatment success at the end of treatment translates to better long-term outcomes.

The evidence that food supplied to poor TB patients might be associated with greater treatment success could be vital for policy makers to make adequate provision for needbased nutrition schemes easily accessible to poor patients across India. Finally, it is im- 
portant to note that this intervention costs as little as $\$ 10$ per month, a small cost relative to that of unsuccessful treatment outcomes. Further studies should explore this effect prospectively using a randomized control trial design with adequate sample size.

\section{Acknowledgements}

The study was undertaken as a part of the "TB Operations Research Training Project" conducted by The International Union against TB and Lung Disease (The Union) with funding support from The Global Fund through Project Axshya. This training project was conceived and implemented by The Union (South-East Asia Regional Office, New Delhi, India) in collaboration with Central TB Division (Directorate General of Health Services, Ministry of Health and Family Welfare, Government of India), the National TB Institute (Directorate General of Health Services, Ministry of Health and Family Welfare, Government of India Bangalore, India), World Health Organization (India Country Office), and U.S. Centers for Disease Control and Prevention (Division of TB Elimination, Atlanta, USA).

Disclaimer: The authors alone are responsible for the views expressed in this publication and they do not necessarily represent the decisions or policies of the World Health Organization, The Union, or U.S. Centers for Disease Control and Prevention.

Contributions: Conception and Design: BS, TV, SC, SP, VKC; Data Collection: BS, KM, SC, MJ, SP; Data analysis: BS, TV, SC, AMK, PKM, JEO, MS, AO, VKC; Writing the manuscript: BS, TV, AMK, PKM, JEO, MS, AO, VKC.

\section{References}

[1] World Health Organization (2015) Global Tuberculosis Report, 2014. WHO, Geneva.

[2] Snowden, F.M. (2008) Emerging and Re-Emerging Diseases: A Historical Perspective. Immunological Reviews, 22, 9-26. https://doi.org/10.1111/j.1600-065X.2008.00677.x

[3] Davies, P.D. (2003) The World-Wide Increase in Tuberculosis: How Demographic Changes, HIV Infection and Increasing Numbers in Poverty Are Increasing Tuberculosis. Annals of Medicine, 35, 235-243. https://doi.org/10.1080/07853890310005713

[4] Benatar, S.R. and Upshur, R. (2010) Tuberculosis and Poverty: What Could (and Should) Be Done? International Journal of Tuberculosis and Lung Disease, 14, 1215-1221.

[5] Tanimura, T., Jaramillo, E., Weil, D., Raviglione, M. and Lönnroth, K. (2014) Financial Burden for Tuberculosis Patients in Low- and Middle-Income Countries: A Systematic Review. European Respiratory Journal, 43, 1763-1775. https://doi.org/10.1183/09031936.00193413

[6] Barter, D.M., Agboola, S.O., Murray, M.B. and Bärnighausen, T. (2012) Tuberculosis and Poverty: The Contribution of Patient Costs in Sub-Saharan Africa-A Systematic Review. BMC Public Health, 12, 980. https://doi.org/10.1186/1471-2458-12-980

[7] Cegielski, J.P. and McMurray, D.N. (2004) The Relationship between Malnutrition and Tuberculosis: Evidence from Studies in Humans and Experimental Animals. International Journal of Tuberculosis and Lung Disease, 8, 286-298.

[8] Macallan, D.C. (1999) Malnutrition in Tuberculosis. Diagnostic Microbiology and Infectious Disease, 34, 153-157. https://doi.org/10.1016/S0732-8893(99)00007-3

[9] Lönnroth, K., Williams, B.G., Cegielski, P. and Dye, C. (2010) A Consistent Log-Linear Re- 
lationship between Tuberculosis Incidence and Body Mass Index. International Journal of Epidemiology, 39, 149-155. https://doi.org/10.1093/ije/dyp308

[10] Van Lettow, M., Fawzi, W.W. and Semba, R.D. (2003) Triple Trouble: The Role of Malnutrition in Tuberculosis and Human Immunodeficiency Virus Co-Infection. Nutrition Reviews, 61, 81-90. https://doi.org/10.1301/nr.2003.marr.81-90

[11] Zachariah, R., Spielmann, M.P., Harries, A.D. and Salaniponi, F.M. (2002) Moderate to Severe Malnutrition in Patients with Tuberculosis Is a Risk Factor Associated with Early Death. Transactions of the Royal Society of Tropical Medicine and Hygiene, 96, 291-294. https://doi.org/10.1016/S0035-9203(02)90103-3

[12] The Union (SEARO) (2010) International Union against Tuberculosis and Lung Disease: Report of the Consultative Workshop on Tuberculosis and Poverty Delhi.

[13] Kamineni, V.V., et al. (2012) Addressing Poverty through Disease Control Programmes: Examples from Tuberculosis Control in India. International Journal for Equity in Health, 11, 17. https://doi.org/10.1186/1475-9276-11-17

[14] Bhargava, A., et al. (2013) Nutritional Status of Adult Patients with Pulmonary Tuberculosis in Rural Central India and Its Association with Mortality. PLoS ONE, 8, e77979. https://doi.org/10.1371/journal.pone.0077979

[15] Sudarsanam, T.D., et al. (2011) Pilot Randomized Trial of Nutritional Supplementation in Patients with Tuberculosis and HIV-Tuberculosis Coinfection Receiving Directly Observed Short-Course Chemotherapy for Tuberculosis. Tropical Medicine \& International Health, 16, 699-706. https://doi.org/10.1111/j.1365-3156.2011.02761.x

[16] Nelson, M., Peter, M. and Paul, M.K. (2009) Food Incentives to Improve Completion of Tuberculosis Treatment: Randomised Controlled Trial in Dili, Timor-Leste. BMJ, 339, b4248. https://doi.org/10.1136/bmj.b4248

[17] Sinclair, D., Abba, K., Grobler, L. and Sudarsanam, T.D. (2011) Nutritional Supplements for People Being Treated for Active Tuberculosis. Cochrane Database of Systematic Reviews, No. 11, CD006086. https://doi.org/10.1002/14651858.CD006086.pub3

[18] Directorate of Census Operations West Bengal 2011. www.censusindia.gov.in/2011census/dchb/1911_PART_B_DCHB_NORTH\%20TWENTY \%20FOUR\%20PARGANAS.pdf www.censusindia.gov.in/2011census/dchb/1917_PART_B_DCHB_SOUTH\%20TWENTY\% 20FOUR\%20PARGANAS.pdf

[19] HDRCC Development and Planning Department Government of West Bengal (2010) District Human Development Report: North 24 Parganas. Development and Planning Department Government of West Bengal.

[20] HDRCC Development and Planning Department Government of West Bengal (2009) District Human Development Report: South 24 Parganas. Development and Planning Department Government of West Bengal. 
Submit or recommend next manuscript to SCIRP and we will provide best service for you:

Accepting pre-submission inquiries through Email, Facebook, LinkedIn, Twitter, etc. A wide selection of journals (inclusive of 9 subjects, more than 200 journals)

Providing 24-hour high-quality service

User-friendly online submission system

Fair and swift peer-review system

Efficient typesetting and proofreading procedure

Display of the result of downloads and visits, as well as the number of cited articles

Maximum dissemination of your research work

Submit your manuscript at: http://papersubmission.scirp.org/

Orcontact 迆@scirp.org 